\title{
Use of Gamithromycin for the Treatment of Osteomyelitis Secondary to Foot Rot in a Sheep
}

\author{
Geórgia Camargo Góss', Claudia Acosta Duarte', Tiago Gallina Correa³, Ingrid Rios Lima Machado², \\ Fabricio Desconsi Mozzaquatro', Cláudia Medeiros Rodrigues"', Rafaela da Silveira Prestes ${ }^{2}$ \& Gabriela Döwich ${ }^{1}$
}

\begin{abstract}
Background: Lameness is one of the main causes of economic losses in sheep breeding, especially in the distal region of the limbs. Poor sanitation management, especially in terms of hygiene conditions and the introduction of animals without previous preventive care, is an important predisposing factor in sheep flocks. Interdigital phlegmon (foot rot) is a bacterial disease that causes pain, heat, edema, hyperemia in the region, and can lead to secondary processes such as osteomyelitis. This case report describes the use of gamithromycin for the treatment of osteomyelitis secondary to foot rot in a sheep. Case: An Ile-de-France ewe exhibiting signs of lameness, pain, heat, hyperemia and edema in the four digits was treated at the Veterinary Hospital of UNIPAMPA. The lesions were characterized by interdigital phlegmon, commonly known as foot rot, and the right thoracic limb was more affected, exuding a foul odor and purulent secretion. The affected limbs were treated topically with an antiseptic solution. The lesions healed completely except for the right thoracic limb, whose clinical condition worsened. Osteitis was suspected, and was confirmed by radiographic evaluation of the region. Treatment with ceftiofur was introduced, but proved to be ineffective. Nevertheless, the lesion was found to have worsened, and a new X-ray evaluation was made, which revealed dislocation of the distal phalanx as well as involvement of the middle and proximal phalanges. Thus, we decided to perform chemical arthrodesis of the distal interphalangeal joint. Before beginning this procedure, contrast X-rays were taken that revealed the development of a fistulous pathway connecting the distal interphalangeal joint to the proximal interphalangeal joint, which precluded this procedure. In view of the worsening of the condition, amputation of the distal and middle phalanges was performed, as well as scraping of the distal edge of the proximal phalanx. In the postoperative period, ceftiofur was used as antibiotic therapy and flunixin meglumine as analgesic, in addition to daily dressings with topical iodine. After this procedure, there was no improvement in lameness and the radiographic images showed worsening of the clinical condition. At this time, the antimicrobial therapy was replaced with tylosin. After beginning treatment with this antimicrobial, there was a slight decrease in lameness, but a fistulous pathway with purulent secretion was formed in the region corresponding to the distal portion of the first phalanx, as well as an increase in the bone lesion, which was observed radiographically. Due to the ineffectiveness of the drug therapy, it was replaced by gamithromycin, which was applied three times. After beginning this treatment, lameness receded and the wound stopped producing purulent secretion, and at the end of the applications of this active ingredient, there was complete resolution of lameness and improvement of the radiographic signs of the animal of this case report.

Discussion: Antimicrobial therapy is an important factor in the treatment of interdigital phlegmon and of osteomyelitis, and should be performed properly using broad-spectrum antibiotics. In the case reported here, although antibiotics with those characteristics were used, the active ingredient had to be changed more than once. In this particular case, there was an improvement in the lameness and the wound, and in the radiographic signs of the proximal phalanx, only after the application of gamithromycin. Therefore, this drug can be considered as an alternative for the treatment of osteomyelitis in ruminants, especially in cases unresponsive to treatment with other antibiotics.
\end{abstract}

Keywords: gamithromycin, foot rot, osteomyelitis, sheep. 


\section{INTRODUCTION}

Lameness is a significant cause of economic losses in sheep farming, especially with regard to infectious diseases of the hoof [17]. Predisposing factors of these conditions are the purchase of animals from locations that lack technical monitoring, introduction into the flock of individuals that have not been quarantined, and poor hygiene conditions of the facilities [15]. Interdigital phlegmon, commonly known as foot rot [4], is a serious disease of sheep caused by the anaerobic bacterium Dichelobacter nodosus in animals previously infected by Fusobacterium necrophorum, a Gramnegative bacterium [10]. Clinically, foot rot manifests as fissures and signs of interdigital caseous necrosis, diffuse localized edema, moderate to severe pain, and a fetid odor [3]. Bacterial infections may give rise to osteomyelitis, contributing to the emergence of lameness in large animals. This makes treatment based on broadspectrum antibiotic therapy difficult [5]. The drugs most commonly used for the treatment of this condition are penicillin, ceftiofur and macrolide class antibiotics [12].

This report describes the use of gamithromycin in the treatment of osteomyelitis secondary to interdigital phlegmon in a sheep.

\section{CASE}

An Ile-de-France ewe, approximately 6 yearold and weighing $50 \mathrm{~kg}$, was treated at the University Veterinary Hospital (HUVet UNIPAMPA). The animal was referred to the veterinary hospital for postpartum care and treatment of interdigital phlegmon in all the limbs. The most severely affected was the right thoracic limb, which presented an open wound with purulent secretion in the border region between the skin and the coronary band on the medial side of the middle phalanx.

Localized treatment of all the limbs was started with topical povidone iodine (Iodo Polividona Tópico $\left.{ }^{\circledR}\right)^{1}$ and a hydantoin-based repellent (Formoped $\left.{ }^{\circledR}\right)^{2}$. After 6 days of this treatment, the lesions of the pelvic limbs and the left thoracic limb had healed completely, but the lesion in the right thoracic limb had worsened and the animal presented grade 5 lameness. There was clinical suspicion of osteomyelitis in this hoof, which was confirmed by simple X-ray examination of the lateromedial and dorsopalmar projections of the affected region. The radiographic analysis revealed cortical bone irregularity with loss of opacity and of the trabecular pattern of the distal phalanx (P3), characterized by small areas of bone lysis, and the discovery of osteitis in the P3 of the affected foot. Antibiotic treatment was started using ceftiofur $\left(\mathrm{CEF} 50^{\circledR}\right)^{3}[2 \mathrm{mg} / \mathrm{kg}]$ once daily for nine days, and analgesia using phenylbutazone (Butafenil $\left.{ }^{\circledR}\right)^{4}$ [ $5 \mathrm{mg} / \mathrm{kg}$ ] once daily for three days.

After this period, the lesion looked worse and new X-ray examinations indicated that the condition had become even more severe. The radiographic findings showed areas of permeable bone lysis in the body and distal portion of $\mathrm{P} 3$, together with irregular periosteal reaction and loss of corticomedullary transition in the distal portion, as well as P3 dislocation. The middle phalanx (P2) also showed areas of irregular osteolysis in a region of bone marrow in the body and localized irregular periosteal reaction.

The proximal phalanx (P1) showed an irregular periosteal reaction, affecting its distal portion. These findings corroborate the radiographic diagnosis of osteomyelitis in P2 and P1. In view of the worsening of the condition and the lack of response to antimicrobial treatment, it was initially decided to maintain the digit through the application of chemical arthrodesis at the distal interphalangeal joint. For this procedure, given the radiographic findings, contrast radiography was performed to confirm the absence of communication between the joints of the distal portion of the limb, and after injecting iodinated contrast in the distal interphalangeal joint, the contrast medium was found to progress to the distal border of the P1. In view of the severity of the lesion and constant worsening of the condition, the medial digit of the right thoracic limb was amputated through the removal of P3 and P2.

As the P1 was also involved, its distal border was scraped, with intraoperative radiographic monitoring. In the postoperative period, antibiotic treatment with ceftiofur $\left(\mathrm{CEF} 50^{\circledR}\right)^{3}$ at $2 \mathrm{mg} / \mathrm{kg}$, was applied once a day for 27 days and analgesia with phenylbutazone (Butafenil $\left.{ }^{\circledR}\right)^{4}$ at $5 \mathrm{mg} /$ $\mathrm{kg}$ once daily for seven days. For three days after surgery, the animal presented grade 3 lameness and was treated with povidone topical iodine through a drain inserted in the surgical site. After removal of this drain, there was suture dehiscence, presence of purulent secretion, return of the lameness to grade 5, and worsening of the P1 bone lesion, which was revealed by a radiographic study that showed an increase in irregular periosteal reaction of the bone and bone lysis of the body and its distal end. Tylosin $\left(\text { Tyladen }^{\circledR}\right)^{5}$ at $15 \mathrm{mg} / \mathrm{kg}$, was administered once a day for 10 days as antimicrobial treatment. 
The surgical wound showed considerable improvement and lameness receded to grade 2. However, the formation of a fistulous pathway originating in the middle region of $\mathrm{P} 1$, and a large quantity of purulent secretion, were observed. Until this time, the wound was kept closed and it was decided to treat it as an open wound. As the purulent secretion did not decrease, antibiotic treatment with gamithromycin $\left(\text { Zactran }^{\circledR}\right)^{6}$ at $6 \mathrm{mg} / \mathrm{kg}$ was applied, in a total of three applications with a $48 \mathrm{~h}$ interval between them. Twentyfour $h$ after the first application, the amount of purulent secretion had decreased considerably. After the second application, the purulent secretion had disappeared, and 4 days after the third application, the wound was completely healed. Radiographically, it was observed that between day 0 (first application of gamithromycin) and day 15 there was no increase in the periosteal bone reactions and areas of bone lysis. However, between day 15 and day 30, there was a slight regression of the bone lesion, which was radiographically visible by the presence of regular and non-invasive periosteal reactions, which, together with the presence of bone sclerosis in the distal portion of P1, characterize the process of reorganization, bone neoformation and lesion stability. Besides the radiographic findings, the sheep presented no lameness and was therefore discharged.

\section{DISCUSSION}

Lameness in ruminants may be structural, functional or infectious, leading to significant economic losses due to declining production, early disposal of animals, and expenses with treatments that are often long and expensive [1]. Hence, such treatment is limited to animals that are zootechnically valuable, like the animal of this case report. It is therefore important to describe effective therapeutic options that can reduce drug costs.

The initial clinical signs of foot rot are lameness, edema, hyperemia and local hyperthermia, as well as the presence of pockets of purulent secretion in the interdigital space and, as the disease progresses, intensification of the signs until fistulas are formed [15]. This evolution was not observed here, since the most affected digit already had a fistulated wound, while the lesions in the other limbs were clinically resolved before the condition worsened. The development of the disease by the primary agent Dichelobacter nodosus necessarily requires a previous infection by Fusobacterium necrophorum [13].

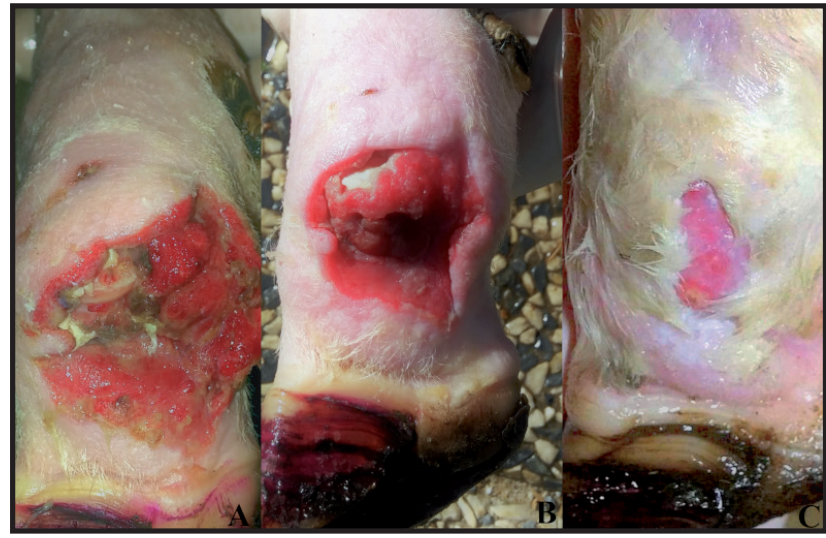

Figure 1. Aspect of the wound after amputation of P3 and P2. A- Surgical would during treatment with ceftiofur. B- Surgical would after treatment with tylosin. C- Surgical would after treatment with gamithromycin.

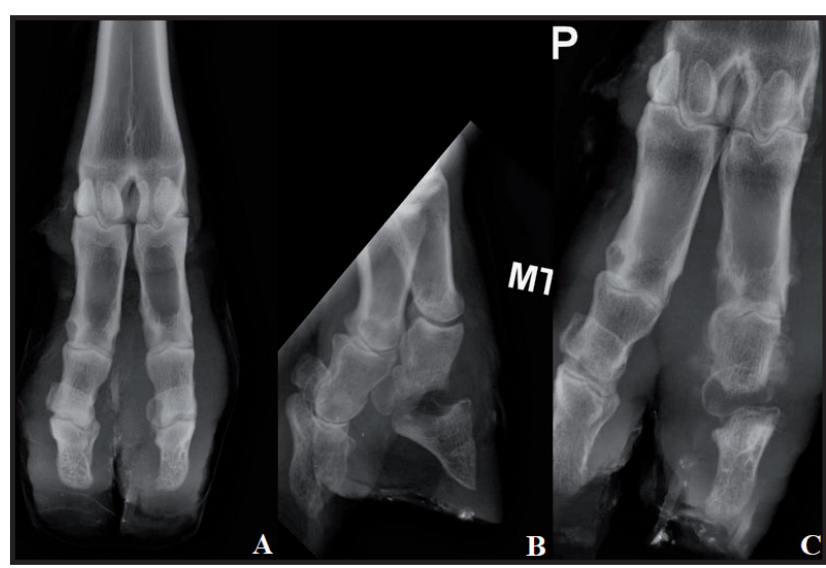

Figure 2. Radiographic monitoring of the right thoracic limb. ADorsopalmar projection: beginning of lesion in P3; note the increase in trabeculations. B- Lateromedial projection: note the dislocation in P3 and periosteal reactions in P2. C- Dorsopalmar projection: note the dislocation of $\mathrm{P} 3$ and the periosteal reactions throughout the body of $\mathrm{P} 2$ and the distal portion of $\mathrm{P} 1$.

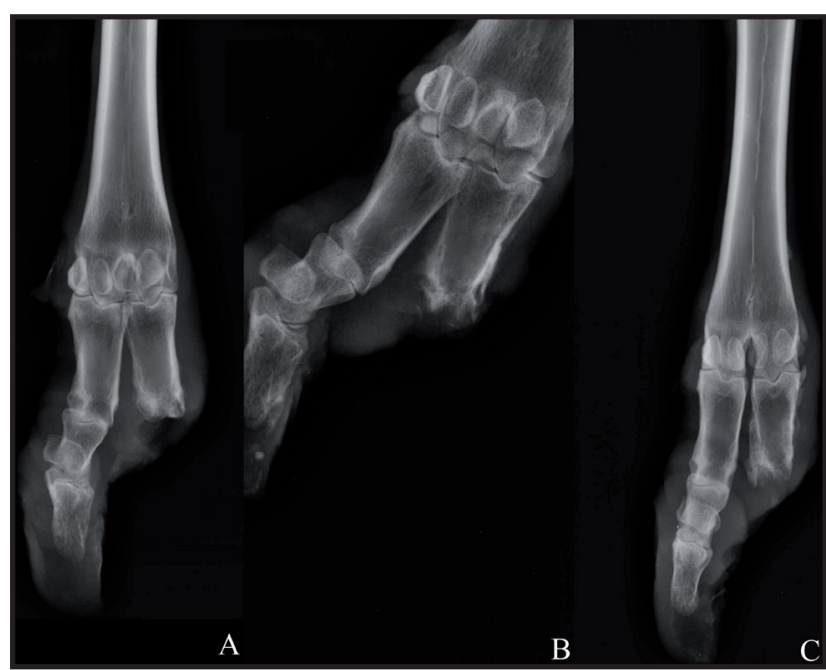

Figure 3. Radiographic monitoring of lateromedial projections of the sheep's right thoracic limb. A- Note the immediate post-surgical appearance of P1 after scraping of its distal portion. B- Appearance of P1 two weeks after treatment with gamithromycin; note the irregularity of the bone edges. C-Appearance of P1 45 days after treatment with gamithromycin; note the smooth appearance of the bone edges and regression of the periosteal reaction. 
The sheep of this case report was kept on pastures of Eragrostis plana along with other animals at sites with moist soil. These conditions are a predisposing factor for the occurrence of the disease [14], since moisture promotes the maceration of tissues, facilitating infection by F. necrophorum [13]. Thus, sheep flocks should be kept on pastures with low moisture to prevent this condition [13], in addition to regular hoof trimming and zinc sulfate foot bathing of the entire herd, taking care to separate affected animals from healthy ones. Treatment with topical and/or systemic antibiotics associated with the segregation of diseased animals [8] and wound care [4] is indicated.

Osteomyelitis develops secondary to bacterial or fungal infections, leading to severe lameness when it affects the limbs. The treatment basically consists of broad-spectrum antibiotic treatment [7], as was done with the animal of this report. In this case, all the antibiotics used here were recommended for the treatment of bacterial infections in ruminants $[10,11,14]$. Ceftiofur, a third-generation cephalosporin with a broad spectrum of activity [2] is considered safe and effective [11]. However, the results obtained in this case were not satisfactory.

Although the macrolide tylosin is more effective on gram-positive microorganisms [10], it was partially effective here, reducing the sheep's lameness and helping to heal the surgical wound. However, neither of these drugs were sufficiently effective to control and reverse the bone lesions in the case in question.
Gamithromycin, also a macrolide, differs from the other active ingredients of the same class of antibiotics because it is bactericidal. When applied subcutaneously, it is rapidly absorbed and distributed [9], and one of its main indications is for the treatment of respiratory diseases in cattle [6]. Recently, it has also been shown that a dose of $6 \mathrm{mg} / \mathrm{kg}$ of gamithromycin is effective in eliminating the occurrence of interdigital phlegmon [5,14]. Although we found no information in the literature about the use of this antimicrobial for the treatment and regression of osteomyelitis in ruminants, this drug showed good efficacy in the reported case.

Thus, studies about the pharmacokinetics and bioavailability of gamithromycin in bone tissues are necessary, even though this drug was effective in the treatment of this condition in the case reported here, and its use as a therapeutic alternative can be envisaged in bone infections non-responsive to other treatments.

\section{MANUFACTURERS}

\author{
${ }^{1}$ VicPharma Indústria e Comércio Ltda. Taquaritinga, SP, Brazil. \\ ${ }^{2}$ Zoetis Brasil - Saúde Animal Ltda. Campinas, SP, Brazil. \\ ${ }^{3}$ Agener União Saúde Animal Ltda., São José dos Campos, SP, \\ Brazil. \\ ${ }^{4}$ Hertape Saúde Animal Ltda. Juatuba, MG, Brazil. \\ ${ }^{5}$ Ceva Saúde Animal Ltda. Paulínia, SP, Brazil. \\ ${ }^{6}$ Boehringer Ingelheim do Brasil Ltda. Itapecerica da Serra, SP, \\ Brazil.
}

Declaration of interest. The authors report no conflicts of interest. The authors alone are responsible for the content and writing of this paper.

\section{REFERENCES}

1 Alvarez J.C. 2003. Alteraciones digitales en el ganado bovino del trópico bajo. MVZ-Córdoba. 8(1): 249-253.

2 Andrade S.F., Giuffrida R. \& Ribeiro M.G. 2008. Quimioterápicos antimicrobianos e antibióticos. In: Andrade S.F. (Ed). Manual de Terapêutica Veterinária. 3.ed. São Paulo: Roca, pp.14-57.

3 Berry S.L. 2001. Diseases of the digital soft tissues. Veterinary Clinics of North America: Food Animal Practice. 17(1): 129-142.

4 Greenough P.R. 2007. Infectious diseases and other conditions affecting the interdigital space. In: Greenough P.R. (Ed). Lameness in cattle. 5th edn. Philadelphia: Saunders, pp. 199-220.

5 Forbes A.B., Strobel H. \& Stamphoj I. 2014. Field studies on the elimination of foot rot in sheep through whole flock treatments with gamithromycin. Veterinary Records. 174: 146.

6 Giguère S., Huang R., Malinski T.J., Dorr P.M., Tessman R.K. \& Somerville B.A. 2011. Disposition of gamithromycin in plasma, pulmonary epithelial lining fluid, bronchoalveolar cells, and lung tissue in cattle. American Journal of Veterinary Research. 72(3): 326-330.

7 Hoogan P.A. \& Honnas C.M. 2010. Osteomielitis. In: Smith B.P. (Ed). Medicina Interna de Grandes Animales. 4.ed. Barcelona: Elsevier, pp.1213-1216.

8 Hosie B. 2004. Foot rot and lameness in sheep. The Veterinary Record. 154: 37-38. 
9 Huang R.A., Letendre L.T., Banav N., Fisher J. \& Somerville B. 2010. Pharmacokinetics of gamithromycin in cattle with comparison of plasma and lung tissue concentrations and plasma antibacterial activity. Journal of Veterinary Pharmacology and Therapeutics. 33: 227-237.

10 Islam M.S., Rahman M.M., Bhuyian M.M.U., Shamsuddin M. \& Islam M.T. 2016. Efficacy of oxytetracycline, amoxicillin, sulfamethoxazole and trimethoprim, and tylosin for the treatment of bacterial diseases in cattle and goats. Bangladesh Journal of Veterinary Medicine. 14(1): 47-51.

11 Kausche F.M. \& Robb E.J. 2003. A comprehensive review of ceftiofur sodium and hydrochloride formulations for treatment of bovine foot rot. Veterinary Therapeutics. 4(1): 83-93.

12 Radostitis O.M., Gay C.C., Hinchicliff K.W. \& Constable P.D. Diseases of the musculoskeletal system. In: Radostitis O.M., Gay C.C., Hinchcliff K.W. \& Constable P.D. (Eds). Veterinary Medicine - A textbook of the diseases of cattle, sheep, goats, pigs and horses. 10th edn. Philadelphia: Elsevier, pp.635-638.

13 Riet-Correa F., Simões S.V.D. \& Azevedo E.D. 2011. Principais enfermidades de caprinos e ovinos no semiárido brasileiro. In: XV Congresso Latinoamericano de Buiatria (Paysandú, Uruguay). pp.13-15.

14 Sargison N.D. \& Scott P.R. 2011. Metaphylatic gamithromycin treatment for the management of lameness in ewes putatively caused by Bacteroides melaninogenicus. Veterinary Record. 169: 556.

15 Silva L.A.F., Moraes R.R., Romani A.F., Fioravanti M.C.S., Cunha P.H.J., Borges J.R.J., Macedo S.P., Damasceno A.D., Rabelo R.E. \& Garcia A.M. 2006. Pododermatite séptica em bovinos: evolução clínica da fase inicial. Brazilian Journal of Veterinary Research and Animal Science. 43(5): 674-680.

16 Silva L.A.F., Silva L.M., Romani A.F., Rabelo R.E., Fioravanti M.C.S., Souza T.M. \& Silva C.A. 2001. Características clínicas e epidemiológicas das enfermidades podais em vacas lactantes do município de Orizona - GO. Ciência Animal Brasileira. 2(2): 119-126.

17 Winter A.C. 2008. Lameness in sheep. Small Ruminant Research. 76: 149-153. 